\title{
Erratum to: Design, synthesis, in vitro cytotoxicity evaluation and structure-activity relationship of Goniothalamin analogs
}

\author{
Mazlin Mohideen · Suraya Zulkepli • Nik-Salmah Nik-Salleh • Li Hui Leong • \\ Kok Meng Chan - Salmaan Hussain Inayat-Hussain · Mohd Zulkefeli • \\ Jean-Frédéric F. Weber • A. F. M. Motiur Rahman
}

Published online: 17 May 2013

(c) The Pharmaceutical Society of Korea 2013

Erratum to: Arch. Pharm. Res.

DOI 10.1007/s12272-013-0099-1

Unfortunately, not all the authors contributing to the article were included in the author group in the originally published article.

The complete list of contributing authors appears in this erratum.
The name of Dr. Weber is misspelled and should read as Jean-Frédéric F. Weber.

The Acknowledgement section missing from the article is now included as well.

Acknowledgments This work was supported by grants from the Ministry of Science, Technology and Innovation, Malaysia (MOSTI) (Biotech Grant Number-30600007001) and the National University of Malaysia (NN-015-2007).

The online version of the original article can be found under doi:10.1007/s12272-013-0099-1.

M. Mohideen · S. Zulkepli · N.-S. Nik-Salleh · M. Zulkefeli ·

J.-F. F. Weber - A. F. M. M. Rahman

Atta-ur-Rahman Institute for Natural Products Discovery,

Faculty of Pharmacy, Universiti Teknologi MARA (UiTM),

Puncak Alam Campus, 42300 Bandar Puncak Alam,

Selangor D. E., Malaysia

L. H. Leong - K. M. Chan - S. H. Inayat-Hussain

Department of Biomedical Science, Faculty of Allied Health

Sciences, National University of Malaysia (UKM), Jalan Raja

Muda Abdul Aziz, 50300 Kuala Lumpur, Malaysia

A. F. M. M. Rahman ( $\square)$

Department of Pharmaceutical Chemistry, College of Pharmacy,

King Saud University, Riyadh 11451, Saudi Arabia

e-mail: afmrahman@ksu.edu.sa 